\title{
Down syndrome phonology: Developmental patterns and intervention strategies
}

\author{
Carol Stoel-Gammon \\ Department of Speech and Hearing Sciences, University of Washington, USA
}

\begin{abstract}
This paper describes phonological development in children with Down syndrome paying particular attention to underlying deficits and intervention strategies. The first section provides an overview of factors believed to influence phonological development in this population. The second section describes four aspects of Down syndrome phonology: (I) the prelinguistic stage; (2) the transition to speech; (3) the phonology of the single words; and (4) phonological characteristics of conversational speech with a focus on intelligibility. Intervention strategies associated with each aspect are also presented. Children with Down syndrome are slow to acquire the phonological system of their mother tongue. In spite of normal or nearly normal prelinguistic development, these children are delayed in the use of meaningful speech and slow to acquire a productive vocabulary. In some cases their speech remains unintelligible throughout childhood and adolescence, making it difficult to communicate with those around them. The purpose of this paper is to summarize research on phonological development of children with Down syndrome with attention to underlying deficits and to the speech characteristics of prelinguistic vocalisations as well as words and conversation. Current views on intervention are also described.
\end{abstract}

Keywords - Down syndrome, phonological development, prelinguistic development, intelligibility, intervention

\section{Factors affecting phonological acquisition}

The phonological systems of children with Down syndrome are influenced by a variety of factors that can create difficulties perceiving and producing speech. In addition to the cognitive deficit that is the primary marker of the syndrome, hearing loss and differences in anatomy and physiology are contributing factors. Input may also be implicated. The precise influence of each factor is difficult to determine and may vary from one child to another. In conjunction, however, these factors have deleterious effects on speech and language development.

\section{Hearing loss}

Infants and children with Down syndrome often suffer from mild-to-moderate hearing loss. Downs (1980) reported that $78 \%$ of the children she tested were found to have "hearing problems" in one or both ears when criteria for a "problem" was a $15 \mathrm{~dB}$ loss. Of the children with a hearing problem, $65 \%$ displayed significant levels of loss in both ears; $54 \%$ evidenced conductive loss; $16 \%$ had sensorineural loss in one or both ears; and $8 \%$ displayed mixed losses. It was once believed that hearing loss in the mild-to-mod- erate range had little effect on language acquisition; however, research on otitis media in infants has shown that losses of this magnitude can negatively affect speech and language development (Friel-Patti \& Finitzo, 1990; Mody, Schwartz, Gravel, \& Ruben, 1999; Nittrouer, 1996; Roberts, 1997; Wallace, Gravel, McCarton, \& Ruben, 1988). Given the other deficits faced by children with Down syndrome, it is likely that recurrent hearing loss compromises their language learning environment and that greater degrees of hearing loss and/or extended periods of middle ear disease will be associated with poorer outcomes on speech and language measures. In her review of language among children and adolescents with Down syndrome, Chapman (1997) notes that much of the variation in communicative abilities can be better understood if hearing status is taken into account.

In terms of intervention related to hearing status, the needs are clear: infants and children with Down syndrome will benefit from an aggressive treatment for hearing loss associated with middle ear pathology. Balkany (1980) identified three goals of such treatment: (1) normalization of hearing through insertion of tympanostomy tubes and, in some cases, fitting of hearing aids; (2) interruption of the cycle of recurrent otitis media with effusion through use of pro- 
phylactic drugs; and (3) prevention of chronic ear disease through adequate otologic care. In addition, Yarter (1980) suggested that infants and young children also receive an auditory training program concurrently with their program of speech therapy.

\section{Differences in anatomy and physiology}

Individuals with Down syndrome have skeletal and muscular systems that differ from those individuals without Down syndrome (Leddy, 1999; Miller \& Leddy, 1998). For oral structures, the skeletal system is characterized by absent or deficient bone growth, a smaller oral cavity, and more posterior tongue carriage; the muscular system is characterized by absent and extra muscles in the facial region and a large muscular tongue. These differences in structure and in tongue size influence the production of lingual consonants. Furthermore, weak facial muscles limit lip movement, thus affecting production of labial consonants and rounded vowels. General hypotonicity affects lip and tongue movements involved in all aspects of speech production. Any one of these factors is likely to influence motor movements associated with speech, and negatively impact the articulatory and phonatory abilities of children with Down syndrome.

The nervous system of individuals with Down syndrome also has distinctive characteristics including anatomical differences in the central and peripheral nervous system, reduced brain size and weight, smaller and fewer sulci, narrower superior temporal gyrus, fewer cortical neurons, decreased neuronal density, delayed neuronal myelination; abnormal dendrite structures; and altered cellular membranes (Leddy, 1999; Miller, 1988; Miller \& Leddy, 1998; Rast \& Harris, 1985; Yarter, 1980). It is hypothesised that these differences are associated with disruptions in the accuracy, speed, consistency and economy of speech movements.

The influence of anatomical and physiological characteristics on speech development of children with Down syndrome was examined by Miller and colleagues (Miller, Miolo, Sedey, Pierce, \& Rosin, 1989). Using Robbins and Klee's protocol (1987) to assess the speech motor abilities of 43 children with Down syndrome, the researchers found a high correlation between speech motor function and the number of different words produced by children with Down syndrome in a spontaneous speech sample. Specifically, the speech function scores obtained at the first data collection session (when the children were 18-60 months of age) accounted for nearly $80 \%$ of the variance in predicting the number of different words in samples collected approximately 5 months later. The researchers concluded that speech motor function and phonetic inventory were the best speech predictors of vocabulary diversity 18 months later. As was the case with hearing status, it appears that variation in speech and language skills of children with Down syndrome can be attributed to their speech motor abilities which, in turn, are related to anatomical and physiological characteristics.
In terms of intervention in this domain, Yarter (1980) suggested that techniques for improving speech-motor deficits related to hypotonicity and possible hyposensitivity of the lip should be initiated in the first year of life and advocated lip stimulation and exercises designed to strengthen the sucking response through use of a straw. Kumin, Councill and Goodman (1994) suggested strengthening the orofacial musculature through a program of lip massage, and bubble and whistle blowing for young children. The most controversial intervention in this domain is surgery for tongue reduction. Parsons, Iacono and Rozner (1987) report the results of a study in which 18 children with Down syndrome underwent tongue-reduction surgery as a means of increasing articulatory proficiency. The children's articulatory skills were assessed pre- and post-operatively, and at a 6-month follow-up; no significant differences in the number of articulation errors were found. In addition, the articulation scores of the children undergoing the surgery were not significantly different than the scores of a non-surgery group of children with Down syndrome. In spite of the lack of change in articulatory skills for either group, parents of children in both groups claimed that their children's speech had improved at the 6-month follow-up assessment.

\section{Language learning environment}

A third factor that may affect phonological development of children with Down syndrome is the nature of linguistic input they receive. Current theory holds that language acquisition is the result of a process of social interaction involving shared activities, and that the rate and quality of caregivers' language play key roles in language acquisition (Warren \& Yoder, 1997). Research shows that vocal and verbal interactions between caregivers and children with Down syndrome differ from interactions involving typically developing children in a number of respects. For the most part, findings show that adult input is less well suited to the vocal and verbal abilities of children with Down syndrome(Lynch \& Eilers, 1991; Miller, 1987).

Differences include more "vocal clashing" in "proto-conversations" of infancy, suggesting that the rhythm of turntaking exchanges is disrupted (Berger \& Cunningham, 1983); maternal speech that is produced more rapidly and includes a higher proportion of nouns, shorter utterances, more imperatives, and more grammatically incomplete sentences (Buckholt, Rutherford, \& Goldberg, 1978; Buium, Rynders, \& Turnure, 1974); and mother-child interactions that are primarily mother-directed (Cardoso-Martins \& Mervis, 1985). Although these findings suggest that the input to children with Down syndrome may be less than optimal in terms of creating an enriched environment for learning to talk, Rosenberg and Abbeduto (1993) note that the majority of investigations of input to children with learning disabilities are plagued by methodological flaws. In particular, they find little evidence of a causal relationship between features of adult input and acquisition. 
Two studies have specifically examined phonological characteristics of speech to infants and toddlers with Down syndrome. An investigation by Velleman, Mangipudi and Locke (1989) reported that, compared with mothers of typically developing infants and toddlers, the mothers of children with Down syndrome produced significantly fewer phonetically contingent responses to their children's utterances (i.e., responses that reproduced the segmental and/or prosodic characteristics of the child's vocalization). This finding takes on special significance in light of an earlier investigation showing that mothers' use of sound expansions and imitations in speech to their 17-month-old infants with Down syndrome (i.e., phonological modelling) was correlated positively with the children's expressive language at 3 years of age (L. Smith \& von Tetzchner, 1986; L. Smith, von Tetzchner \& Michalson, 1988). If L. Smith's finding about phonological modelling is replicated in other investigations, parents and caregivers should be encouraged to increase this type of input to their infants and toddlers with Down syndrome.

\section{Prelinguistic vocal development}

Investigations of prespeech development suggest that infants with Down syndrome are nearly typical in this domain. Both cross-sectional and longitudinal studies using various measures and analysis techniques have documented strong similarities in the amount of vocalization produced; in the developmental timetable, particularly age at onset of canonical babble; and in the characteristics of consonants and vowels occurring in canonical babble (Dodd, 1972; Oller \& Seibert, 1988; B.L. Smith \& Oller, 1981; B.L. Smith \& Stoel-Gammon 1996; Steffens, Oller, Lynch \& Urbano, 1992)

Although the majority of investigations have shown no differences between prelinguistic development of infants with Down syndrome and their non-Down syndrome peers, Lynch and colleagues (Lynch, Oller, Steffens, Levine, Basinger, \& Umbel, 1995) reported that the average age of onset of canonical babbling among the infants with Down syndrome was about 9 months, approximately two months later than the age for the typically developing infants, and that the proportional occurrence of canonical babbling was less stable for the infants with Down syndrome. Because hypotonicity and delays in motor development are characteristic of Down syndrome, the relative instability in canonical babbling may be a consequence of deficits in the motor domain. These findings notwithstanding, one can conclude that Down syndrome appears to have relatively little effect on prelinguistic vocal development. In large measure, developmental patterns are within typical range although the babbling period for infants with Down syndrome is much longer, often extending through the second year of life.

\section{The transition to speech}

According to the typical developmental timetable, children's first words generally appear around the end of the first year and overlap with canonical babble for a period of 6-8 months. In a longitudinal study of typically developing infants, Robb, Bauer, and Tyler (1994) reported that when their subjects had a productive vocabulary of about 10 different words, the proportion of words and babble in their spontaneous productions was roughly equal. When the productive vocabulary reached 50 words, at around 18 months of age, the ratio of words to babble was about three to one.

During the transition to speech, the phonetic characteristics of babble and speech are highly similar (Locke, 1983; Stoel-Gammon, 1998). Specifically, the types of consonants that occur most frequently in late babbling, namely, stops, nasals and glides, also predominate in early word productions, while the consonants that are infrequent in babble, liquids, fricatives, and affricates, are precisely those that appear later in the acquisition of meaningful speech (Stoel-Gammon, 1985). Moreover, the consonant-vowel syllable structure which is characteristic of the canonical babbling period is also the most frequent syllabic type in early word productions. Thus, among the typically developing population, babbling and early speech share the same basic phonetic properties in terms of sound types and syllable shapes.

Not only do babble and early words share phonetic characteristics during the transition to speech, there is a growing body of evidence linking prelinguistic vocal development with general speech and language skills throughout early childhood (Stoel-Gammon, 1992, 1998). In general, increased use of complex babble in the prelinguistic period is linked to better performance on the speech and language measures after the onset of speech and in the years that follow. These findings suggest that babbling serves as a foundation for the acquisition of speech and language; Stoel-Gammon (1998) hypothesised that infants who produce more babble, particularly more canonical utterances with a variety of consonants and vowels, have amassed a greater arsenal of "building blocks" that can be recruited for the production of a variety of words.

Given that prelinguistic vocal development of infants with Down syndrome is typical in most respects, and that prelinguistic development is closely linked to early linguistic development, one might expect that early language acquisition among infants with Down syndrome would be nearly typical. This, however, is not the case. Most children with Down syndrome exhibit a substantial delay in the appearance of first words, in spite of their normal babbling patterns. Stray-Gunderson (1986), for example, noted extreme variability in the age at which children with Down syndrome produced their first words. Some children produced words as early as 9 months (chronological age), within the range for children with typical development, whereas for others, the first words did not appear until the age of 7 years (chronological age). The observed delays in 
onset of meaningful speech and the wide disparity in the age of onset are presumably associated with a number of factors described in the previous section.

Information regarding the transition from babble to speech in infants with Down syndrome comes from work by B.L. Smith $(1977 ; 1984)$ whose longitudinal data, collected in a laboratory setting, showed that the average age of onset of meaningful speech (i.e. occurrence of productions judged to be recognizable words) was 14 months for the typically developing infants and 21 months for the infants with Down syndrome, a difference of 7 months. Moreover, at 14 months approximately $13 \%$ of the utterances of the typically developing group were judged to be attempts at meaningful speech; at 18 months of age, about half the utterances produced by this group were classified as meaningful. By comparison, only $2 \%$ of the utterances produced by 21 -month-old infants with Down syndrome were judged to be meaningful (by experimenters and/or parents), and at 30 months the proportion of meaningful utterances remained under $5 \%$.

The findings of Buckley (2000) extend our understanding of lexical acquisition in Down syndrome children. Her data show that vocabulary growth is quite slow. At 24 months of age, the average productive vocabulary was 28 words (compared with 250 for a typically developing child). At 3 years, the mean vocabulary was 116 words, rising to 248 words at 4 years, to 272 words at 5 years, and 330 words at 6 years, an age at which the child with typical development has a productive vocabulary of several thousand words. In terms of early lexical acquisition, the child with typical development achieves a productive vocabulary of about 250 words at two years of age; among children with Down syndrome, this milestone is not attained until two years later, at the age of four years.

Taken together, the research by Buckley and B.L. Smith indicates that the onset of meaningful speech is significantly delayed in the infants with Down syndrome and that after the appearance of words, growth of productive vocabulary is exceedingly slow. Other investigations of lexical acquisition in children with Down syndrome have shown that even when the Down syndrome group is matched to a typically developing control group on mental (rather than chronological) age, lexical acquisition in children with Down syndrome is delayed (Chapman, 1997).

In terms of intervention strategies appropriate for the transition to speech, the focus should be on supporting lexical acquisition by increasing the child's awareness of the use of sounds as meaningful elements in communication. Specifically, caregivers (i.e. parents, child-care workers, teachers) should encourage the use of words by producing phonetically contingent responses to non-meaningful vocalisations; for example, caregivers might repeat the child's non meaningful utterance [ba] and link it to the phonetically similar word "ball", thus increasing the likelihood of [ba] being used as a meaningful utterance. In addition, caregivers can play "sound games" to make infants and toddlers aware of speech sounds and of sound-meaning relationships with the goal of increasing the child's repertoire of speech sounds and syllable shapes.

\section{The phonology of single words}

In general, word productions of children with Down syndrome have the same phonological characteristics as those of children with typical development (Dodd \& Leahy, 1989; Rosenberg \& Abbeduto, 1993). In particular, stop, nasal and glide consonants tend to be produced accurately while fricatives, affricates and liquids are often in error (Bleile \& Schwarz, 1984; B.L. Smith, 1984; Stoel-Gammon, 1980, 1981). Phonological process analyses have also highlighted similarities between children with Down syndrome and those with typical development with the following patterns occurring frequently: (1) consonant clusters are produced as singleton consonants; (2) word-final consonants are omitted; (3) target fricatives and affricates are produced as stops; (4) aspirated voiceless stops in initial position are deaspirated; (5) word-initial liquids are produced as glides and word-final liquids are produced as vowels or are omitted; and (6) word-final voiced obstruents are devoiced (Van Borsel, 1996; Cholmain, 1994; Dodd, 1976; Kumin, Councill \& Goodman, 1994; Mackay \& Hodson, 1982; B.L. Smith \& Stoel-Gammon, 1983; StoelGammon, 1980, 1981).

As might be expected, however, phonological acquisition in children with Down syndrome proceeds more slowly than in their cognitively typical peers. B.L. Smith and StoelGammon (1983) calculated the rate of suppression of four phonological processes in their longitudinal study. They reported that, in the children developing typically, average percentage of occurrence of the processes declined from $63 \%$ at $18-24$ months to $25 \%$ at $30-36$ months, representing a change of about $38 \%$ in a 12 -month period. By comparison, the average percentage of occurrence of the same processes in the speech of children with Down syndrome was $61 \%$ when the children were 3 -years-old, declining to $40 \%$ at the age of 6 years, an average change per year of $6 \%$ compared with $38 \%$ for the children with typical development. Even when the children with Down syndrome achieve a mental age of 7 or 8 years, errors characteristic of younger children are still present. Errors documented for young children with Down syndrome tend to persist through adolescence and even adulthood (Shriberg \& Widder, 1990; Sommers, Reinhart \& Sistrunk, 1988; Sommers, Patterson \& Wildgen, 1988).

In addition to persisting longer, error patterns for children with Down syndrome are also more variable than for children with typical development. Dodd (1976) compared the phonological systems of three groups of children matched for mental age: typically developing, children with severe learning difficulties and children with Down syndrome. Although there were no statistical differences in the number and type of phonological errors occurring in spontaneous and imitated productions of the typically developing children and those with severe learning difficuties, the performance of children with Down syndrome exhibited several 
differences: they made a greater number of phonological errors in their productions; their errors were more inconsistent; and a greater proportion of their errors could not be described by a set of common phonological processes. Furthermore, these children made fewer errors in imitated than in spontaneous productions than children in the other groups. Dodd $(1975 ; 1976)$ suggested that these findings provide evidence of a difficulty in motor speech programming in children with Down syndrome, perhaps related to a general deficit in their motor abilities. Stoel-Gammon (1981) also reported greater variability in errors produced by Down syndrome participants. She noted, for example, that children with typical development move from incorrect to correct phoneme production in a linear fashion with a small set of substitution types. In contrast, among children with Down syndrome, there was a greater range of substitution types and these varied from one word to another.

In terms of intervention for single-word productions, most programs focus on increasing the phonetic repertoire and reducing the number of errors, using therapy techniques similar to those for children with phonological delay or disorder. Of particular interest is a study by Cholmain (1994) who described a therapy program for young children with Down syndrome (chronological age $4 ; 1-5 ; 6$ ) with unintelligible speech, and language ages ranging from $1 ; 4$ to $2 ; 10$. The program provided children with "simple uncluttered examples of the organisation of the sounds in the language in order to encourage them to construe the phonological system" (p. 16). Based on the therapy principles advocated by Hodson and Paden (1983), key elements of the program included listening and production practice focused on particular phonemes and phonological processes, with therapy occurring in the clinic and at home. In spite of the low language ages of the children involved in the study, results showed change in their phonological systems within the first two weeks of beginning therapy despite minimal change in the previous 3-12 months. Most notably, there were dramatic increases in the measure of Percent Consonant Correct, with pre-therapy figures ranging from 3-38\% and post-therapy figures (6-14 weeks later) ranging from $19-88 \%$. In addition, there were marked improvements in the children's use of grammatical forms. The author concluded that the therapy approach allowed the children to restructure their sounds systems and proceed in syntax development.

Another type of therapy program focused on the variability of word productions by children with Down syndrome (Dodd \& Leahy, 1989; Dodd, McCormack \& Woodyatt, 1994). This approach differed from traditional intervention programs in two ways: the unit of treatment was whole words rather than phonemes or phonological processes and parents served as the agents of therapy. Parents were instructed to accept only one pronunciation for a set of words individually selected for their child. Acceptable pronunciations did not necessarily need to be correct; however, the words with errors had to be consistently produced and errors had to be "developmental" rather than "deviant." Results indicated that, over the 13 week program, the four children in the study showed "exceptional improvement" in the number of consonants produced correctly. Moreover, the mean proportion of "deviant" errors reduced from around $70 \%$ to $41 \%$ during this period. Although the numbers of participants in these studies was relatively limited, the findings are promising.

\section{Speech intelligibility}

At the age four years, the speech of most children with typical development is fully intelligible, even though their phonological systems are not yet complete (Coplan \& Gleason, 1988). By comparison, the speech of some individuals with Down syndrome tends to be unintelligible throughout their lives even though their mental age may exceed four years (Kumin 1994; Pueschel \& Hopman, 1993; Rosin, Swift, Bless \& Vetter, 1988; Shriberg \& Widder, 1990). Long-standing difficulties with intelligibility can presumably be attributed to phonological patterns associated with Down syndrome.

Two studies have examined parents' perceptions of the speech and language skills of their children with Down syndrome. Kumin's (1994) analysis of 937 parent questionnaires revealed that nearly $60 \%$ of parents reported that their children (aged birth to $40+$ years) "frequently" had difficulty being understood. An additional 37\% reported that their children "sometimes" had difficulty being understood. When asked to indicate which speech skills were particularly troublesome for their children, articulation was ranked highest with $80 \%$ of the parents noting difficulties in this area. Pueschel and Hopman (1993) also used a questionnaire to gain information on the parents' views of their children's speech and language skills. Although parents reported that their children were generally capable of making themselves understood, 71-94\% of parents of children aged 4-21 years noted that their offspring had problems with articulation. It is likely that the perceived levels of unintelligibility are associated with variable phoneme production noted in the previous section, a factor which increases the difficulty for identifying a target word. In addition, atypical prosodic patterns, as reported by Shriberg and Widder (1990), are often associated with decrease in speech intelligibility.

There are few intervention programs for children with Down syndrome aimed specifically at increasing intelligibility (but see Swift \& Rosin, 1990), and treatment for language, at least in the United States, is often part of more general educational programs designed to teach "life skills". The ultimate goal of such programs is to allow individuals with learning disabilities to live independently and work in the community. In the domain of speech and language, efforts are often directed toward increasing the functional communication skills necessary for social interactions and vocational training with little emphasis on phonology skills perse.

Although learning "life skills" is important, the emphasis on functional communication at the expense of more focused phonological therapy is open to question. Shriberg 
and Widder (1990) argue that in spite of the slow progress of children with Down syndrome and the limited resources of speech therapists and special education teachers, articulation therapy should remain as a high priority throughout childhood and adolescence. These authors note that improving the segmental and suprasegmental aspects of speech would increase intelligibility, which in turn would benefit social and vocational elements of individuals with learning difficulties. In a similar vein, Fowler (1995) recommends to parents that they invest in speech therapy stating that it "will provide your child with a greater sense of power to be understood.” (p. 129). In closing, it should be remembered that speech therapy need not be the exclusive domain of therapists; parents, caregivers and educators can also be trained to serve as agents of therapy thereby broadening the contexts in which therapy occurs and increasing the amount of intervention a child receives. In terms of phonology, long-term intervention, first for the transition to words, then for single word articulation skills, and finally for conversational speech, is to be encouraged.

\section{Correspondence}

Carol Stoel-Gammon - Department of Speech and Hearing Sciences, University of Washington, 1417 N.E. 42nd Street, Seattle, WA 98105-6246, USA - Fax: + I-206-543-1093・ E-mail:csg@u.washington.edu

\section{References}

Balkany, T. J. (1980). Otologic aspects of Down's syndrome. Seminars in Speech, Language and Hearing, 1, 39-48.

Berger, J., \& Cunningham, C. C. (1983). Development of early vocal behaviors and interactions in Down's syndrome and nonhandicapped infant-mother pairs. Developmental Psychology, 19, 322-331.

Bleile, K., \& Schwarz, I. (1984). Three perspectives on the speech of children with Down syndrome. Journal of Communication Disorders, 17, 87-94.

Buckholt, J. A., Rutherford, R. B., \& Goldberg, K. E. (1978). Verbal and nonverbal interaction of mothers with their Down's syndrome and nonretarded infants. American Journal of Mental Deficiency, 82, 337-343.

Buckley, S. (2000) Teaching reading to develop speech and language. Presented at the $3 \mathrm{rd}$ International Conference on Language and Cognition in Down Syndrome, Portsmouth, UK, September 6-8.

Buium, N., Rynders, J., \& Turnure, J. (1974). Early maternal linguistic environment of normal and non-normal language-learning children. American Journal of Mental Deficiency, 79, 52-58.

Cardoso-Martins, C., \& Mervis, C. B. (1985). Maternal speech to prelinguistic children with Down syndrome. American Journal of Mental Deficiency, 89, 451-458.

Chapman, R. S. (1997). Language development in children and adolescents with Down syndrome. Mental Retardation and Developmental Disabilities Research Reviews, 3 (4), 307-312..

Cholmain, C. N. (1994). Working on phonology with young children with Down syndrome. Journal of Clinical Speech and Language Studies, 1, 14-35.
Coplan, J., \& Gleason, J. (1988). Unclear speech: Recognition and significance of unintelligible speech in preschool children. Pediatrics, 82, 447-452.

Dodd, B. J. (1972). Comparison of babbling patterns in normal and Down-syndrome infants. Journal of Mental Deficiency Research, 16, 35-40.

Dodd, B. J. (1975). Recognition and reproduction of words by Down's syndrome and non-Down's syndrome retarded children. American Journal of Mental Deficiency, 80, 306-311.

Dodd, B. J. (1976). A comparison of the phonological systems of mental age matched normal, severely abnormal and Down's syndrome children. British Journal of Disorders of Communication, 11, 27-42.

Dodd, B. J., \& Leahy, P. (1989). Phonological disorders and mental handicap. In M. Beveridge, G. Conti-Ramsden, \& I. Leudar (Eds.), Language and Communication in Mentally Handicapped People (pp. 33-56). London: Chapman and Hall.

Dodd, B., McCormack, P. \& Woodyatt, G. (1994). Evaluation of an intervention program: Relation between children's phonology and parents' communicative behavior. American Journal of Mental Retardation, 98(5), 632-645.

Downs, M. P. (1980). The hearing of Down's individuals. Seminars in Speech, Language and Hearing, 1, 25-37.

Fowler, A. (1995). Linguistic variability in persons with Down syndrome: Research and implications. In L. Nadel \& D. Rosenthal (Eds.), Down Syndrome: Living and Learning in the Community (pp. 121-131). New York: Wiley-Liss Inc.

Friel-Patti, S. \& Finitzo, T. (1990). Language learning in a prospective study of otitis media with effusion in the first tow years of life. Journal of Speech, Language, and Hearing Research, 33, 188-194.

Hodson, B. W. \& Paden, E.P. (1983). Targeting Intelligible Speech. San Diego: College Hill Press.

Kumin, L. (1994). Intelligibility of speech in children with Down syndrome in natural settings: Parents' perspective. Perceptual and Motor Skills, 78, 307-313.

Kumin, L., Councill, C., \& Goodman, M. (1994). A longitudinal study of the emergence of phonemes in children with Down syndrome. Journal of Communication Disorders, 27, 265-275.

Leddy, M. (1999). The biological bases of speech in people with Down syndrome. In J. F. Miller, M. Leddy, \& L. A. Leavitt (Eds.), Improving the Communication of People with Down Syndrome (pp. 61-80). Baltimore: Paul H. Brookes.

Locke, J. L. (1983). Phonological Acquisition and Change. New York: Academic Press.

Lynch, M., \& Eilers, R. E. (1991). Perspectives on early language from typical development and Down syndrome. In N. W. Bray (Ed.), International Review of Research on Mental Retardation: Vol. 17 (pp. 55-90). New York: Academic Press.

Lynch, M. P., Oller, D. K., Steffens, M. L., Levine, S. L., Basinger, D. L., \& Umbel, V. M. (1995). Development of speech-like vocalizations in infants with Down syndrome. American Journal of Mental Retardation, 100, 68-86. 
Mackay, L., \& Hodson, B. (1982). Phonological process identification of misarticulations of mentally retarded children. Journal of Communication Disorders, 15, 243-250.

Miller, J. F. (1987). Language and communication characteristics of children with Down syndrome. In S. Pueschel, C. Tinghey, J. Rynders, A. Crocker, \& C. Crutcher (Eds.), New Perspectives on Down Syndrome (pp. 233-262). Baltimore: Brookes Publishing.

Miller, J. F. (1988). The developmental asynchrony of language development in children with Down syndrome. In L. Nadel (Ed.), The Psychobiology of Down Syndrome (pp. 167-198). Cambridge, MA: MIT Press.

Miller, J. F., \& Leddy, M. (1998) Down syndrome: the impact of speech production on language development. In R. Paul (Ed.), Communication and Language Intervention: Vol. 8. Exploring the Speech-Language Connection (pp. 163-177). Baltimore: Paul H. Brookes.

Miller, J.F., Miolo, G., Sedey, A., Pierce, K., \& Rosin, M (1989) Predicting lexical growth in children with Down syndrome. Poster presented at the Annual Meeting of the American Speech-Language-Hearing Association, St. Louis, MO.

Mody, M., Schwarz, R., Gravel, J., \& Ruben, R. (1999). Journal of Speech, Language and Hearing Research, 42, 1069-1079.

Nittrouer, S. (1996). The relationship between speech perception and phonemic awareness: Evidence from low SES children and children with chronic OM. Journal of Speech and Hearing Research, 39, 1059-1070.

Oller, D.K. \& Seibert, J.M. (1988). Babbling of prelinguistic mentally retarded children. American Journal on Mental Retardation, 92, 369-375.

Parsons, C. L., Iacono, T. A., \& Rozner, L. (1987). Effect of tongue reduction on articulation in children with Down syndrome. American Journal of Mental Deficiency, 91, 328-332.

Pueschel, S., \& Hopman, M. (1993). Speech and language abilities of children with Down syndrome. In A. P. Kaiser \& D.B. Gray (Eds.), Enhancing Children's Communication (pp. 335-362). Baltimore: Paul H. Brookes.

Rast, M. M., \& Harris, S. R. (1985). Motor control in infants with Down syndrome. Developmental Medicine and Child Neurology, 27, 675-685.

Roberts, K. (1997). A preliminary account of the effect of otitis media on 15-month-olds' categorization and some implications for early language learning. Journal of Speech, Language and Hearing Research, 40, 508-518.

Robb, M. L., Bauer, H. R., \& Tyler, A. A. (1994). A quantitative analysis of the single word stage. First Language, 14, 37-48.

Robbins, J., \& Klee, T. (1987). Clinical assessment of oropharyngeal motor development in young children. Journal of Speech and Hearing Disorders, 52, 271-277.

Rosenberg, S., \& Abbeduto, L. (1993). Language and Communication in Mental Retardation: Development, Process, and Intervention. Hillsdale, NJ: Lawrence Erlbaum Associates.

Rosin, M. M., Swift, E., Bless, D. \& Vetter, D. K. (1988). Communication profiles of adolescents with Down syndrome. Journal of Childhood Communication Disorders, 12(1), 49-64.
Shriberg, L., \& Widder, C. J. (1990). Speech and prosody characteristics of adults with mental retardation. Journal of Speech and Hearing Research, 33, 627-653.

Smith, B. L. (1977). Phonological development in Down's syndrome children. Paper presented at the 85th Annual Convention of the American Psychological Association, San Francisco, CA.

Smith, B. L. (1984). Implications of infant vocalizations for assessing phonological disorders. In N. J. Lass (Ed.), Speech and Language: Advances in Basic Research: Vol. 11 (pp. 169-194). New York: Academic Press.

Smith, B. L., \& Oller, D. K. (1981). A comparative study of pre-meaningful vocalizations produced by normally developing and Down's syndrome infants. Journal of Speech and Hearing Disorders, 46, 46-51.

Smith, B. L., \& Stoel-Gammon, C. (1983). A longitudinal study of the development of stop consonant production in normal and Down's syndrome children. Journal of Speech and Hearing Disorders, 48, 114-118.

Smith, B. L., \& Stoel-Gammon, C. (1996). A quantitative analysis of the reduplicated and variegated babbling in vocalizations by Down syndrome infants. Clinical Linguistics and Phonetics, 10, 119-130.

Smith, L., \& von Tetzchner, S. (1986). Communicative, sensorimotor and language skill of young children with Down syndrome. American Journal of Mental Deficiency, 91, 57-66.

Smith, L., von Tetzchner, S., \& Michalson, B. (1988). The emergence of language skill in young children with Down syndrome. In L. Nadel (Ed.), The Psychobiology of Down Syndrome (pp. 145-165). Cambridge, MA: MIT Press.

Sommers, R. K., Patterson, J. P. \& Wildgen, P. L. (1988). Phonology of Down syndrome speakers, ages 13-22. Journal of Childhood Communication Disorders, 12(1), 65-91.

Sommers, R. K., Reinhart, R. W., \& Sistrunk, D. A. (1988). Traditional articulation measures of Down syndrome speakers, ages 13-22. Journal of Childhood Communication Disorders, $12(1)$, 93-108.

Steffens, M. L., Oller, D. K., Lynch, M., \& Urbano, R.C. (1992). Vocal development in infants with Down syndrome and infants who are developing normally. American Journal of Mental Retardation, 97, 235-246.

Stoel-Gammon, C. (1980). Phonological analysis of four Down's syndrome children. Applied Psycholinguistics, 1, 31-48.

Stoel-Gammon, C. (1981). Speech development of infants and children with Down's syndrome. In J. K. Darby (Ed.), Speech Evaluation in Medicine (pp. 341-360). New York: Grune and Stratton, Inc.

Stoel-Gammon, C. (1985). Phonetic inventories, 15-24 months: A longitudinal study. Journal of Speech and Hearing Research, 28, 505-512.

Stoel-Gammon, C. (1992). Prelinguistic vocal development: Measurement and predictions. In C. A. Ferguson, L. Menn, \& C. Stoel-Gammon (Eds.), Phonological Development: Models, Research, Implications (pp. 439-456). Timonium, MD: York Press.

Stoel-Gammon, C. (1998). The role of babbling and phonology in early linguistic development. In A. M. Wetherby, S. F. Warren, \& J. Reichle (Eds.), Transitions in Prelin- 
guistic Communication: Preintentional to Intentional and Presymbolic to Symbolic (pp. 87-110). Baltimore: Paul H. Brookes.

Stray-Gunderson, K. (1986). Babies with Down Syndrome: A New Parents Guide. Rockville, MD: Woodbine House.

Swift, E. \& Rosin, P. (1990). A remediation sequence to improve speech intelligibility for students with Down syndrome. Language, Speech, and Hearing Services in Schools, 21, 140-146.

Van Borsel, J. (1996). Articulation in Down's syndrome adolescents and adults. European Journal of Disorders of Communication, 31, 415-444.

Velleman, S., Mangipudi, L., \& Locke, J. (1989) Prelinguistic phonetic contingency: Data from Down syndrome. First Language, 9, 159-174.

Wallace, I. F., Gravel, J. S., McCarton, C. M., \& Ruben, R. J. (1988). Otitis media and language development at 1 year of age. Journal of Speech and Hearing Disorders, 53, 245-251.

Warren, S.F. \& Yoder, P.J. (1997). Emerging model of communication and language intervention. Mental retardation and Developmental Disabilities Research Reviews, 3, 358-362.

Weinberg, B., \& Zlatin, M. (1970). Speaking fundamental frequency characteristics of five- and six-year-old children with mongolism. Journal of Speech and Hearing Research, $13,418-425$.

Yarter, B. H. (1980). Speech and language programs for the Down's population. Seminars in Speech, Language and Hearing, 1, 49-61. 